\title{
Comparison of various types of $k-\epsilon$ models for pollutant emissions around a two-building configuration ${ }^{\text {th }}$
}

\author{
M. Lateb ${ }^{\mathrm{a}, *}$, C. Masson ${ }^{\mathrm{a}}$, T. Stathopoulos ${ }^{\mathrm{b}}$, C. Bédard ${ }^{\mathrm{a}}$ \\ ${ }^{a}$ Department of Mechanical Engineering, ÉTS (École de technologie supérieure) \\ 1100 Notre-Dame West, Montreal, H3C 1 K3 Canada \\ ${ }^{b}$ Department of Building, Civil and Environmental Engineering, Concordia University \\ 1455 de Maisonneuve Blvd. West, Montreal, H3G 1 M8 Canada
}

\begin{abstract}
The dispersion of pollutants exhausted from a building roof stack located in a tower was investigated using various types of $k-\epsilon$ turbulence models, i.e., a standard $k-\epsilon$ model, a RNG $k-\epsilon$ model and a realizable $k-\epsilon$ model, all implemented using Fluent software. In order to determine the turbulence model that best helped reproduce pollutant plume dispersion, the most critical case was considered, namely, when wind blew perpendicularly towards the upstream tower, then placing the building in its wake. When numerical results were compared to wind tunnel experiments, it was found that the realizable $k-\epsilon$ turbulence model yielded the best agreement with wind tunnel results for the lowest stack height, while for the highest stack height, the RNG $k-\epsilon$ turbulence model provided greater concordance with experimental results. The realizable $k-\epsilon$ model was the only model able to provide the correct trend for the concentration distribution in the lower region between the two buildings; however, none of the models reproduced the trend in the upper regions. The standard $k-\epsilon$ model was generally found to be inadequate for reproducing vertical concentration distribution.
\end{abstract}

Keywords: Numerical modelling, pollutant emissions, computational fluid dynamics (CFD), $k-\epsilon$ turbulence models, roof stack pollution

\section{Introduction}

Nowadays, application of Computational Fluid Dynamics (CFD) for atmospheric dispersion processes in the lower region of the Atmospheric Boundary Layer (ABL) is becoming a significant research subject, due to increasing interest in air quality modelling. Full-scale measurement and physical modelling in wind tunnels, have been widely used in studying the dispersion of pollutants (Li and Meroney, 1983a,b; Saathoff et al., 1995; Meroney et al., 1999; Mavroidis et al., 2003; Stathopoulos et al., 2004; Gomes et al., 2007; Stathopoulos et al., 2008; Contini et al., 2009; Nakiboglu et al., 2009; Hajra et al., 2011; Hajra and Stathopoulos, 2012) and most of these experimental studies serve to validate CFD modelling (Murakami et al., 1991; Li and Stathopoulos, 1997; Sada and Sato, 2002; Blocken et al., 2008; Tominaga and Stathopoulos, 2009; Gousseau et al., 2011a,b; Lateb et al., 2011). CFD modelling has already been considered as a powerful tool for predicting the atmospheric dispersion around buildings (Yang and Shao, 2008; Blocken et al., 2011), because it allows for easy control of individual parameters for detailing the process analysis of dispersion. Furthermore, CFD modelling can provide a three-dimensional distribution of the concentration, unlike field and wind tunnel experiments, which only allow to obtain a limited number of point measurements.

\footnotetext{
${ }^{2}$ Portions of the enclosed work were presented at the Fifth International Symposium on Computational Wind Engineering (CWE2010), Chapel Hill, NC, May 23, 2010.

*Corresponding author. Tel.: (+1) 514-396-8800 ext. 7838; Fax: (+1) 514-396-8530.

Email address: mohamed.lateb@etsmtl.ca (M. Lateb)
} 
The performance of CFD modelling predictions for pollutant concentration fields around buildings is crucial to evaluating air quality, and contributing to the comfort, health and the well-being of building occupants in the vicinity of pollutant sources (e.g., rooftop stacks, vents, vehicle exhausts). Its accuracy depends on several parameters that are used in numerical simulations such as turbulence models, grid resolutions, boundary conditions, geometrical representations, and numerical approximations. In this study, the turbulence model was the primary parameter of interest.

Over the past few decades, many CFD simulations of pollutant dispersion have been carried out regarding turbulence modelling parameters for different buildings and stack configurations. Murakami et al. (1991) have compared the computational results obtained using Reynolds Averaged NavierStokes (RANS) standard $k-\epsilon$ and Large Eddy Simulation (LES) turbulence models with the results of wind tunnel experiments. The accuracy of the flow and diffusion fields around a single building and around a complex building has been confirmed via comparison with experimental results. Meroney et al. (1999) compared the Reynolds Stress Model (RSM) and standard and Re-Normalized Group (RNG) $k-\epsilon$ turbulence models with wind tunnel test results, and found that the RSM produced more realistic results than the other two $k-\epsilon$ models. Recently, Blocken et al. (2008) studied pollutant dispersion from a rooftop vent on an isolated cubic building using a combination of the realizable $k-\epsilon$ model and RSM for different turbulent Schmidt numbers. Both turbulence models correctly predicted upstream dispersion, but lateral dispersion was underestimated, compared to wind tunnel results. Tominaga and Stathopoulos (2009) studied the prediction accuracy of the flow and dispersion around a cubic building, using four types of turbulence models (the standard $k-\epsilon$ model, a RNG $k-\epsilon$ model, a $k-\epsilon$ model with Launder and Kato modification, and a realizable $k-\epsilon$ model). They concluded that the standard $k-\epsilon$ model provided inadequate results for the concentration field, and that the RNG $k-\epsilon$ model was the best at providing results that were in general agreement with the experimental data. All turbulence models tested showed poor prediction accuracy for the concentration distribution at the side and leeward walls of the building. More recently, Tominaga and Stathopoulos (2010) compared the performance of RNG $k-\epsilon$ model and LES model for flow and concentration fields around a cube with vent emission in the surface boundary layer. They concluded that, compared to the experimental results, the LES model reproduced concentration distribution better than the conventional RNG $k-\epsilon$ model. In addition, horizontal diffusion was reproduced, since the instantaneous concentration fluctuations were available using the LES approach. The RNG $k-\epsilon$ model underestimated the turbulent diffusion near the cube, which was mainly significant for the reproduction of concentration distribution. Computing time for the unsteady simulations in LES model was 25 times greater than it was in simulations using a RNG $k-\epsilon$ model. For this reason, this parameter must be taken into account when using such a model. Gousseau et al. (2011a) recently evaluated the performance of two different modelling approaches: a standard $k-\epsilon$ and a LES turbulence model, applied to pollutant dispersion in an urban environment. They concluded that the performance of the standard $k-\epsilon$ model strongly depended on the turbulent Schmidt number, and in contrast, the LES model provided better performance without requiring any parameter input in order to solve the dispersion equation. The effects of the near-field pollutant dispersion characteristics of upstream and downstream buildings in an urban environment have recently been examined by Hajra et al. (2011) and Hajra and Stathopoulos (2012), using a wind tunnel simulation and ASHRAE modelling. Both studies showed that height and spacing between the emitter building and its adjacent buildings were critical parameters in the pollutant dispersion process. The authors emphasize the inability of ASHRAE (2007) to model the effect of adjacent buildings, and recommend further investigations of its formulation, whereas they found the ASHRAE (2011) model suitable only for use in specific, limited cases.

In this paper, the results of CFD simulations of pollutant dispersion exhausted from a building roof stack located in the wake of a tower will be described. The simulations were implemented using Fluent CFD software and investigated using various steady RANS $k-\epsilon$ models (standard $k-\epsilon$, RNG $k-\epsilon$ and realizable $k-\epsilon$ turbulence models) which are the models most widely used for many applications (Assimakopoulos et al., 2003; Xie et al., 2005; Salim et al., 2011) including wind loading (Huang et al., 2011) and pollutant transport (Xie et al., 2006). Their capability for producing reasonable predictions 
and acceptable results, as well as their short computational time, have been emphasized by many authors (Lien et al., 2004; Xie et al., 2006; Zhai et al., 2007). Despite the shortcomings of the standard $k-\epsilon$ model, it is robust and simple enough to be tractable numerically (Lien et al., 2006), and is still commonly used in pollutant transport applications (Yassin et al., 2008; Tominaga and Stathopoulos, 2009; Gousseau et al., 2011a; Salim et al., 2011). For these reasons, standard $k-\epsilon$ model testing was planned for a two-building configuration. Special attention was paid to the pollutant concentrations on the emitting building's roof, as well as to those on the roof and leeward wall of the upwind tower. Simulation results were compared to wind tunnel experiments conducted by Stathopoulos et al. (2004) in a boundary layer wind tunnel.

\section{Model description}

The physical model used in this study consists of two lined-up buildings, named the BE building and the Faubourg tower. The tower faces the wind and the BE building is located in the wake region of the tower. Although all buildings up to a distance of $50 \mathrm{~m}$ were included in the experimental model, only the upstream tower is judged to be the main obstacle capable to produce major effects on the overall behaviour of the wind flow and concentration fields around the BE building. Therefore, only these two buildings are considered in the study. The BE building and the tower dimensions are $L_{B E} \times W_{B E} \times H_{B E}=48 \times 53 \times 12.5 \mathrm{~m}^{3}$ and $L_{F b} \times W_{F b} \times H_{F b}=32 \times 53 \times 45 \mathrm{~m}^{3}$, respectively. One structure is located at the roof centre of the tower, and its dimensions are $20 \times 37 \times 5 \mathrm{~m}^{3}$. The BE building has several structures on its roof, but only three of these were deemed of sufficient dimensions to disturb the flow on the roof. These three structures are a penthouse $\left(6.2 \times 18.4 \times 4 \mathrm{~m}^{3}\right)$ an elevator shaft $\left(10 \times 4 \times 4 \mathrm{~m}^{3}\right)$ and a skylight $\left(34.6 \times 6.8 \times 2.2 \mathrm{~m}^{3}\right)$. The other details taken into account in the CFD modelling of the two buildings were the inclined northwest side, the back step at the southeast side for the BE building, and the staircase form of the leeward wall for the Faubourg tower. The stack on the BE roof, from which the pollutant is emitted, sits upstream and is $0.4 \mathrm{~m}$ in diameter; its height varies from $1 \mathrm{~m}$ to $7.2 \mathrm{~m}$. Fig. 1 shows a general view of the buildings and shows details of all dimensions of the physical model under consideration. The origin of the reference frame was set at the centre base of the downstream wall of the BE building, and the positive $x$ direction was opposite to the wind direction.

Elements not taken into account were the entry of the BE building, located on the windward wall, and a parapet 1 metre high, running along the perimeter of the roof. It was decided that the entry did not disturb the flow in the region of interest and, since the parapet had not been reproduced in the wind tunnel experiments, it would not be reproduced in this numerical study.

\section{Mathematical model}

\subsection{Governing equations}

The fundamental equations governing the motion of steady turbulent flows without body forces are the time-averaged Navier-Stokes and continuity equations. For an incompressible flow, they can be written as:

Continuity equation:

$$
\frac{\partial U_{i}}{\partial x_{i}}=0
$$

Momentum equation:

$$
U_{j} \frac{\partial U_{i}}{\partial x_{j}}=\frac{1}{\rho} \frac{\partial}{\partial x_{j}}\left[-P \delta_{i j}+2 \nu S_{i j}-\overline{u_{i} u_{j}}\right]
$$

where $\rho$ is the density of fluid in $\left[\mathrm{kg} \mathrm{m}^{-3}\right], \nu$ the kinematic viscosity in $\left[\mathrm{m}^{2} \mathrm{~s}^{-1}\right], P$ the mean pressure in $\left[\mathrm{kg} \mathrm{m}^{-1} \mathrm{~s}^{-2}\right], S_{i j}$ is the velocity strain rate tensor expressed as $S_{i j}=1 / 2\left(\partial U_{i} / \partial x_{j}+\partial U_{j} / \partial x_{i}\right)$ and $\delta_{i j}$ is the Kronecker delta. $U_{i}$ and $u_{i}$ represent the mean and fluctuating velocity components in $[\mathrm{m}$ $\mathrm{s}^{-1}$, respectively. 


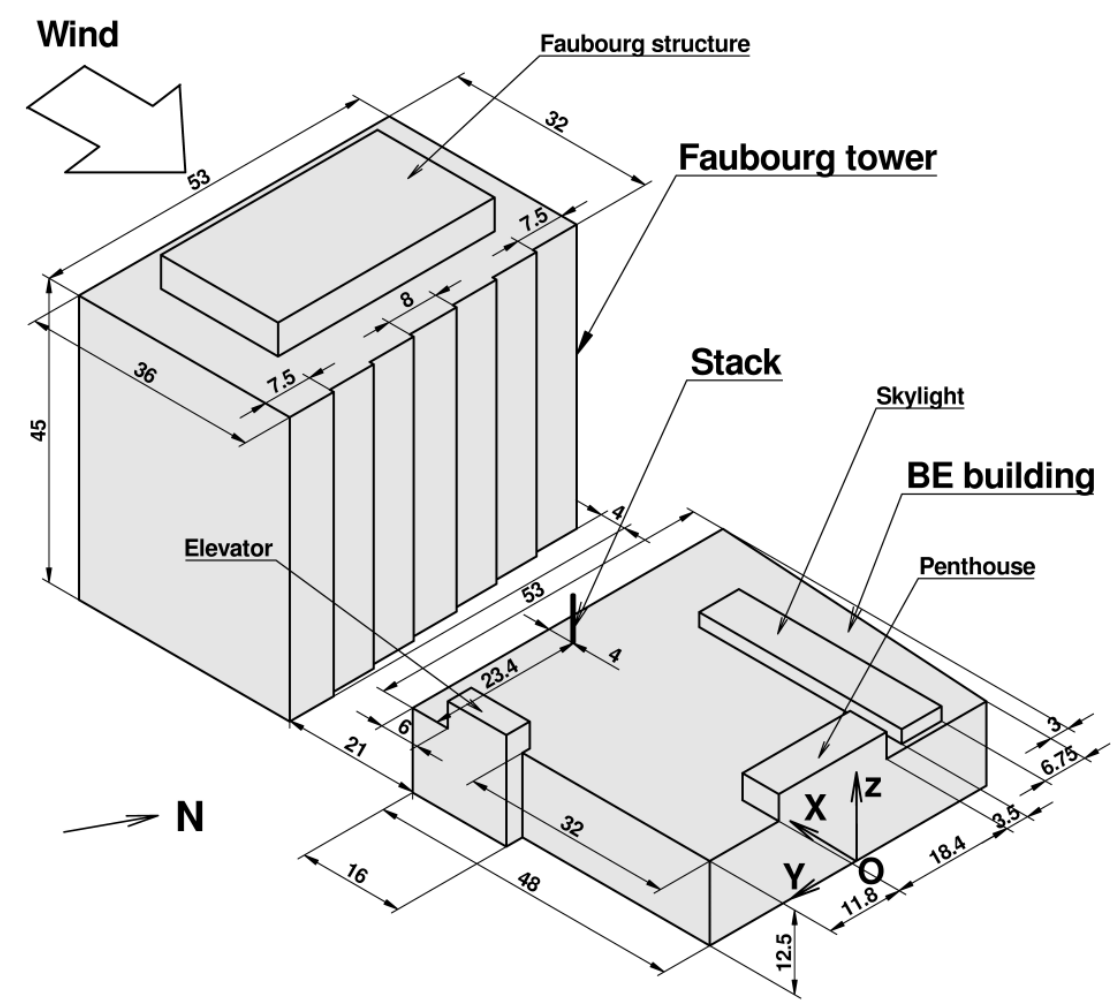

Figure 1: Geometry of the two-building configuration and dimensions in metres.

Through the Reynolds-averaging approach, more variables are introduced, which means that the two equations above are not closed. The Reynolds stress terms $-\overline{u_{i} u_{j}}$ appearing in Eq. (2) represent the diffusive transport of momentum by turbulent motion. These terms need to be determined by a turbulence model before the mean flow equations can be solved. For the various RANS $k-\epsilon$ models compared in this study, i.e., the standard $k-\epsilon$ model (Jones and Launder, 1972; hereafter SKE), the re-normalization group $k-\epsilon$ model (Yakhot et al., 1992; hereafter RNG) and the realizable $k-\epsilon$ model (Shih et al., 1995a; hereafter RLZ), turbulent Reynolds stresses and mean velocity gradients were related by turbulent viscosity using the Boussinesq assumption. The mathematical expression for this is:

$$
-\overline{u_{i} u_{j}}=\nu_{t}\left(\frac{\partial U_{i}}{\partial x_{j}}+\frac{\partial U_{j}}{\partial x_{i}}\right)-\frac{2}{3} k \delta_{i j}
$$

Turbulent kinetic energy $k$ and turbulent dissipation rate $\epsilon$ characterizing the local state of turbulence are related to the turbulent viscosity in the so-called "two equations" model by the following equation:

$$
\nu_{t}=C_{\mu} \frac{k^{2}}{\epsilon}
$$

where $C_{\mu}$ is a parameter that depends upon the turbulence model; turbulent kinetic energy, $k$, is written as:

$$
k=\frac{1}{2} \overline{u_{i}^{2}}
$$

with $\overline{u_{i}^{2}}$ representing the Reynolds normal stresses in the streamwise $x$-, spanwise $y$ - and vertical $z$ directions in $\left[\mathrm{m}^{2} \mathrm{~s}^{-2}\right]$. 


\subsection{Turbulence models}

To close the system of equations, one transport equation for turbulent kinetic energy, $k$, and another for turbulent dissipation rate, $\epsilon$, were added. For the various $k-\epsilon$ turbulence models tested, only the turbulent dissipation rate equation differed. The transport equation for turbulent kinetic energy was the same, and was expressed as follows:

Transport equation of $k$ :

$$
U_{j} \frac{\partial k}{\partial x_{j}}=\frac{\partial}{\partial x_{j}}\left(\frac{\nu_{t}}{\sigma_{k}} \frac{\partial k}{\partial x_{j}}\right)+P_{k}-\epsilon
$$

where $P_{k}$ is the production of turbulent kinetic energy expressed by $P_{k}=\nu_{t} S^{2}, S$ is defined by the velocity strain rate tensor as $S=\sqrt{2 S_{i j} S_{i j}}$ and the constant $\sigma_{k}$ is equal to 1.0 .

In the following sections, the transport equation of the turbulent dissipation rate is detailed for each turbulence model.

\subsubsection{Standard $k-\epsilon$ model}

The turbulent dissipation rate of the SKE $k-\epsilon$ model is expressed by the following equation:

$$
U_{j} \frac{\partial \epsilon}{\partial x_{j}}=\frac{\partial}{\partial x_{j}}\left(\frac{\nu_{t}}{\sigma_{\epsilon}} \frac{\partial \epsilon}{\partial x_{j}}\right)+\frac{\epsilon}{k}\left[C_{\epsilon 1} P_{k}-C_{\epsilon 2} \epsilon\right]
$$

The model constants are $\sigma_{\epsilon}=1.3, C_{\epsilon 1}=1.44$ and $C_{\epsilon 2}=1.92$, and the constant $C_{\mu}$ appearing in Eq. (4) is equal to 0.09 .

\subsection{2. $R N G k-\epsilon$ model}

It is well known that applying a SKE model to complex flows yields poor performance, which in turn limits its scope of applicability (e.g., limitation to high Reynolds numbers, overestimation of $k$ in the impinging regions (Lien et al., 2006)). The RNG model introduces an additional term into the turbulent dissipation rate, $\epsilon$, equation which makes the model more accurate and reliable for a wider class of flows than is the SKE turbulence model (for example, for rapidly strained or swirling flows).

RNG transport equation for $\epsilon$ :

$$
U_{j} \frac{\partial \epsilon}{\partial x_{j}}=\frac{\partial}{\partial x_{j}}\left(\frac{\nu_{t}}{\sigma_{\epsilon}} \frac{\partial \epsilon}{\partial x_{j}}\right)+\frac{\epsilon}{k}\left[C_{\epsilon 1}^{*} P_{k}-C_{\epsilon 2} \epsilon\right]
$$

The turbulent eddy viscosity constant $C_{\mu}$ was set to 0.0845 . The other constants were $\sigma_{\epsilon}=0.719$ and $C_{\epsilon 2}=1.68$, and $C_{\epsilon 1}^{*}$ was expressed by $C_{\epsilon 1}^{*}=1.42-\eta(1-\eta / 4.38) /\left(1+0.012 \eta^{3}\right)$ with:

$$
\eta=\frac{k}{\epsilon} S
$$

\subsubsection{Realizable $k-\epsilon$ model}

This $k-\epsilon$ model consisted of a new model dissipation rate equation and a new realizable eddy viscosity formulation. The realizability effect was achieved by the constant $C_{\mu}$ of the turbulent eddy viscosity, which was no longer a constant but a function of the turbulent fields, mean strain and rotation rates. This model has been extensively validated for a wide range of flows, including boundary layer flows and separated flows.

RLZ transport equation for $\epsilon$ :

$$
U_{j} \frac{\partial \epsilon}{\partial x_{j}}=\frac{\partial}{\partial x_{j}}\left(\frac{\nu_{t}}{\sigma_{\epsilon}} \frac{\partial \epsilon}{\partial x_{j}}\right)+C_{1} S \epsilon-C_{2} \frac{\epsilon^{2}}{k+\sqrt{\nu \epsilon}}
$$

where $\sigma_{\epsilon}=1.2, C_{2}=1.9, C_{1}=\max [0.43, \eta /(\eta+5)]$ with $\eta$ defined as in Eq. (9), and $C_{\mu}=1 /(4.04+$ $\left.\left(A_{s} k U^{*}\right) / \epsilon\right)$ for which $A_{s}=\sqrt{6} \cos \phi, \phi=(1 / 3) \cos ^{-1} \sqrt{6} W, W=S_{i j} S_{j k} S_{k i} / \check{S}^{3}, S=\sqrt{S_{i j} S_{i j}}$, $U^{*}=\sqrt{S_{i j} S_{i j}+\tilde{\Omega}_{i j} \tilde{\Omega}_{i j}}$, and $\tilde{\Omega}_{i j}=\Omega_{i j}-2 \epsilon_{i j} \omega_{k}$. 


\subsection{Dispersion equation}

For the dispersal of a non-buoyant passive scalar contaminant without a source generation rate, the transport equation is:

$$
U_{j} \frac{\partial C}{\partial x_{j}}=\frac{\partial}{\partial x_{i}}\left(-\overline{u_{i} c}\right)
$$

The term $-\overline{u_{i} c}$ appearing in this equation represents the diffusive transport of the concentration by turbulent motion, where $c$ indicates fluctuations of concentration. The turbulent concentration fluxes and the mean concentration gradients are related, using the same analogy as the one used for the Reynolds stress terms, by the following expression:

$$
-\overline{u_{i} c}=\frac{\nu_{t}}{S c_{t}} \frac{\partial C}{\partial x_{i}}
$$

where $S c_{t}$ is the turbulent Schmidt number equal to 0.7 a value commonly used (Tominaga and Stathopoulos, 2007) and further justified in this paper.

\section{Numerical method}

\subsection{Domain size and computational grid}

A staggered rectangular grid system was adopted for this study. The construction of the domain was done according to the instructions recommended by Franke et al. (2007) and Tominaga et al. (2008), and special care was taken in arranging the computational grid cells, as advised by Hefny and Ooka (2009).

Following Celik et al. (2008), three grids were used in order to estimate uncertainty due to discretization: Grid 1, Grid 2 and Grid 3. These had 1.59, 1.99 and 2.29 million cells, respectively. Since the computed concentration obtained for the two successive refined grids were so close (the average error was found to be less than $2 \%$ ), it was determined that further grid refinement would significantly increase processing time with only a negligible increase in accuracy. For this reason, only the results from the calculations using Grid 3 have been included in this paper (for the grid refinement study - see Lateb et al. (2010a)). The computational domain was extended $20.1 H_{F b}$ (streamwise) $\times 10 H_{F b}$ (spanwise) $\times 6.1 H_{F b}$ (height), as shown in Fig. 2 , and was divided into $187 \times 126 \times 102$ grid points, along the $x, y$ and $z$ axes, respectively. The mesh details in the neighbourhood of the two buildings of interest are illustrated in Fig. 3. Note that the grid configuration was created using a stretching ratio of about 1.2 except near the base of the Faubourg tower where the ratio is greater. The choice of this grid was made following several configuration tests carried out in order to obtain the best numerical data as compared with the experimental results. The exhaust cross-section of the stack was divided into 24 cells.

\subsection{Boundary conditions}

Enhanced wall treatment was used for near-wall modelling; according to Wang (2006), it is a better approach for predicting the recirculation zones near the windward edge and in the wake of the building. This wall treatment is called the low-Reynolds number approach; it resolves the viscous sublayer and computes the wall shear stress from the local velocity gradient normal to the wall. It requires a very fine mesh resolution in wall-normal direction. The $\mathrm{Y}^{+}$values obtained close to the walls were within a range of 2 to 5 , which demonstrates the suitability of the grid selected here. At all building walls, the no-slip condition was used assuming smooth wall. Horizontal homogeneity was assured and tested previously in an empty domain by using a specified wall shear stress $\left(\tau_{w}=1.15 \mathrm{~Pa}\right)$ at ground level, as suggested by Blocken et al. (2007). 


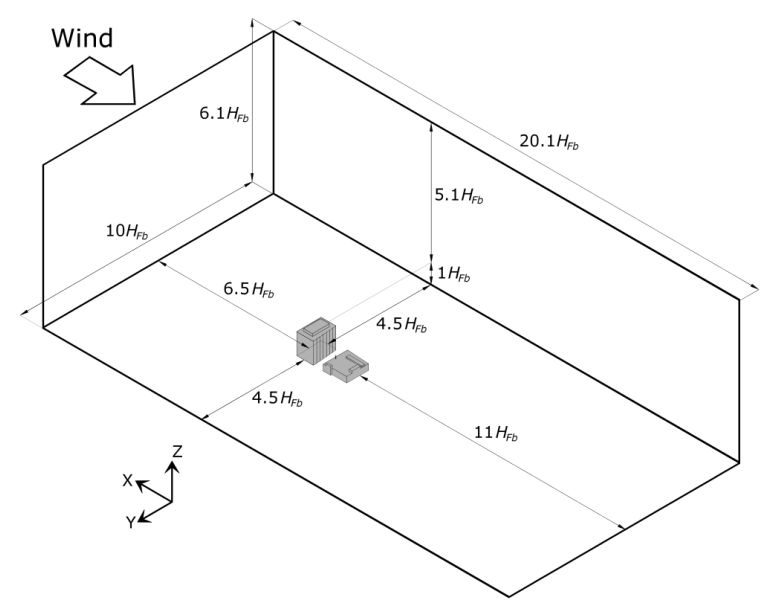

Figure 2: Dimensions of the domain grid.

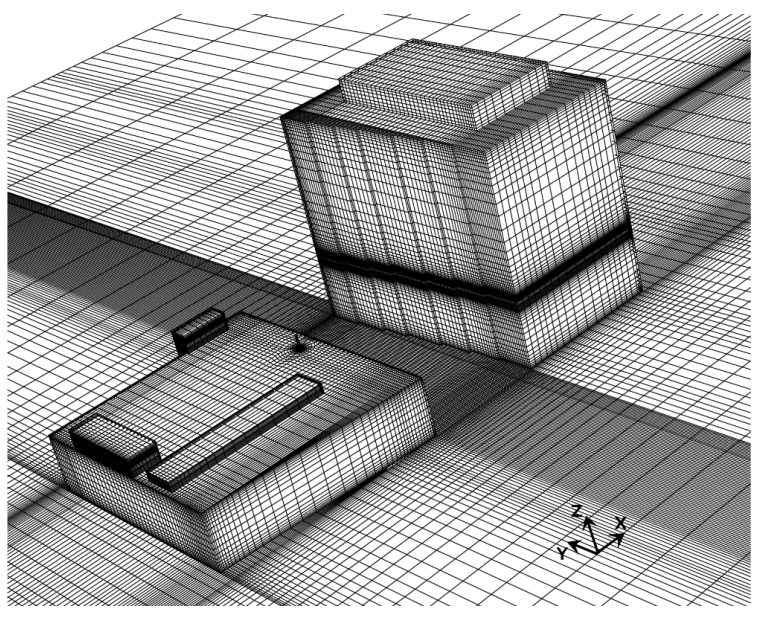

Figure 3: Mesh on the two-building configuration.

At the domain entry, all flow properties were assigned. The different profiles used on this part of the domain are shown in Table 1 . The velocity profile $U(z)$ and the turbulent intensity $T I(z)$ at the inlet were derived from curves proposed by Saathoff et al. (1995). Turbulent kinetic energy and rate of dissipation profiles were deduced from Eqs. (13) to (15)

$$
\begin{gathered}
k(z)=\frac{3}{2}[U(z) T I(z)]^{2} \\
\epsilon(z)=\frac{u^{* 3}}{\kappa z} \\
\frac{U(z)}{u^{*}}=\frac{1}{\kappa} \ln \left(\frac{z}{z_{o}}\right)
\end{gathered}
$$

where $\kappa$ is the Von Karman constant $(=0.42), u^{*}$ the friction velocity $\left(=0.97 \mathrm{~m} \mathrm{~s}^{-1}\right)$ and $z_{o}$ the roughness length at the model scale $\left(z_{o}=0.0033 \mathrm{~m}\right)$ evaluated by Stathopoulos et al. (2004) in the wind tunnel experiments.

Fully developed flow was assumed at the domain exit. The exit plane was located far downstream from the two buildings, so that all parameters in that plane had negligible influence on the velocity and concentration fields calculated in the vicinity of the two buildings. The stack exit conditions were matched as closely as possible to the wind tunnel experiments. The mass flow rates, as well as the concentration and momentum fluxes at the stack exit plane, were those measured experimentally. The pollutant exhaust velocity, $w_{e}$, and its concentration, $C$, were prescribed as uniform, whereas the turbulence intensity, $T I_{s}$, was specified using the following equation (Zhou and Kim, 2010):

$$
T I_{s}=0.16\left(R e_{s}\right)^{-1 / 8}
$$

where $R e_{s}=\left(w_{e} d_{s} \rho_{e}\right) / \mu_{e}$ is the stack Reynolds number, $d_{s}$ refers to the internal diameter of the stack and $\rho_{e}$ and $\mu_{e}$ are the density and dynamic viscosity of the pollutant, respectively.

The stack Reynolds number for the lowest pollutant velocity value, $w_{e}$, was approximately 1940. This value was under the recommended threshold value for reaching the turbulence criterion in the stack. Since all criteria for modelling non-buoyant plume exhaust had been satisfied, Stathopoulos et al. (2004) do not recommend an increase in pollutant exhaust velocity in order to reach the threshold value $\left(R e_{s}>2000\right)$. The wind tunnel results for the concentration measurements were provided in a non-dimensional form; therefore, all the numerical concentrations, $C$, were normalized in the same 
way and were expressed by the following equation:

$$
K=\frac{C U_{H} H_{B E}^{2} 10^{-6}}{Q_{e}}
$$

where $C$ is the mean concentration measured in [ppb], $U_{H}$ is the mean wind velocity at the roof height of the BE building in $\left[\mathrm{m} \mathrm{s}^{-1}\right], H_{B E}$ is the height of the BE building in [m] and $Q_{e}$ is the volumetric flow rate of the pollutant in $\left[\mathrm{m}^{3} \mathrm{~s}^{-1}\right]$.

The simulation parameters used in this study are listed in Table 1 , where $M$ is the momentum ratio (the ratio between the exhaust velocity of the pollutant, $w_{e}$, and the wind velocity at height $H_{B E}$ of the BE building). The different profiles at the inlet as well as the pollutant exit parameters are detailed for the various stack heights considered, i.e., $1 \mathrm{~m}, 3 \mathrm{~m}, 4 \mathrm{~m}$ and $7.2 \mathrm{~m}$. The pollutant concentration at the stack exit, $C_{e}$, is equal to 1 .

\begin{tabular}{|c|c|c|c|c|c|c|c|}
\hline \multirow{2}{*}{$\begin{array}{c}\text { Stack } \\
\text { height } \\
200 h_{s}[\mathrm{~m}]\end{array}$} & \multirow{2}{*}{$\begin{array}{c}\text { Momentum } \\
\text { ratio } \\
M=w_{e} / U_{H}\end{array}$} & \multirow{2}{*}{$\begin{array}{c}\text { Exhaust } \\
\text { velocity } w_{e} \\
{\left[\mathrm{~m} \mathrm{~s}^{-1}\right]}\end{array}$} & \multirow{2}{*}{$\begin{array}{c}\text { Turbulent } \\
\text { intensity } \\
T I_{s}[\%]\end{array}$} & \multicolumn{4}{|c|}{ Profiles at the entry of the domain } \\
\hline & & & & $\begin{array}{c}\text { Profile } \\
U(z)\end{array}$ & $\begin{array}{c}\text { Profile } \\
k(z)\end{array}$ & $\begin{array}{c}\text { Profile } \\
\epsilon(z)\end{array}$ & $\begin{array}{c}\text { Profile } \\
T I(z)\end{array}$ \\
\hline \multirow{2}{*}{1} & 2.2 & 13.88 & 6.2 & \multirow{6}{*}{$14.5 \times z^{0.3}$} & \multirow{6}{*}{$1.25 / z^{0.4}$} & \multirow{6}{*}{$2.17 / z$} & \multirow{6}{*}{$0.063 / z^{0.5}$} \\
\hline & 5 & 31.55 & 5.6 & & & & \\
\hline \multirow{2}{*}{3} & 2.2 & 13.88 & 6.2 & & & & \\
\hline & 4.5 & 28.40 & 5.7 & & & & \\
\hline 4 & 2.2 & 13.88 & 6.2 & & & & \\
\hline 7.2 & 2.2 & 13.88 & 6.2 & & & & \\
\hline
\end{tabular}

Table 1: Simulation test cases and their parameters.

\subsection{Numerical schemes}

The QUICK scheme was used in the discretized momentum equations, and a second-order discretization scheme in other governing equations. The SIMPLE (Semi-Implicit Method for PressureLinked Equations) algorithm (Patankar and Spalding, 1972) was used for introducing pressure into the continuity, and pressure discretization was taken care of by the Standard scheme. In order to reduce the round-off error, a double precision solver was used. Franke et al. (2007) recommend a reduction of the residuals at least four orders of magnitude; hence, the iterative convergence criteria used for reaching the solution was $10^{-5}$.

\section{Results}

In this section, a comparison between the measured and simulated concentrations obtained using the turbulence models tested will be described. The objective was to compare the performance of various turbulence models. This comparison made it possible to produce the concentration distribution of the pollutant operating in the wake region of the two-building configuration of interest. Since no velocity and pressure measurements were available, in the following sections, only the numerical concentration values will be compared to the wind tunnel measurements. 

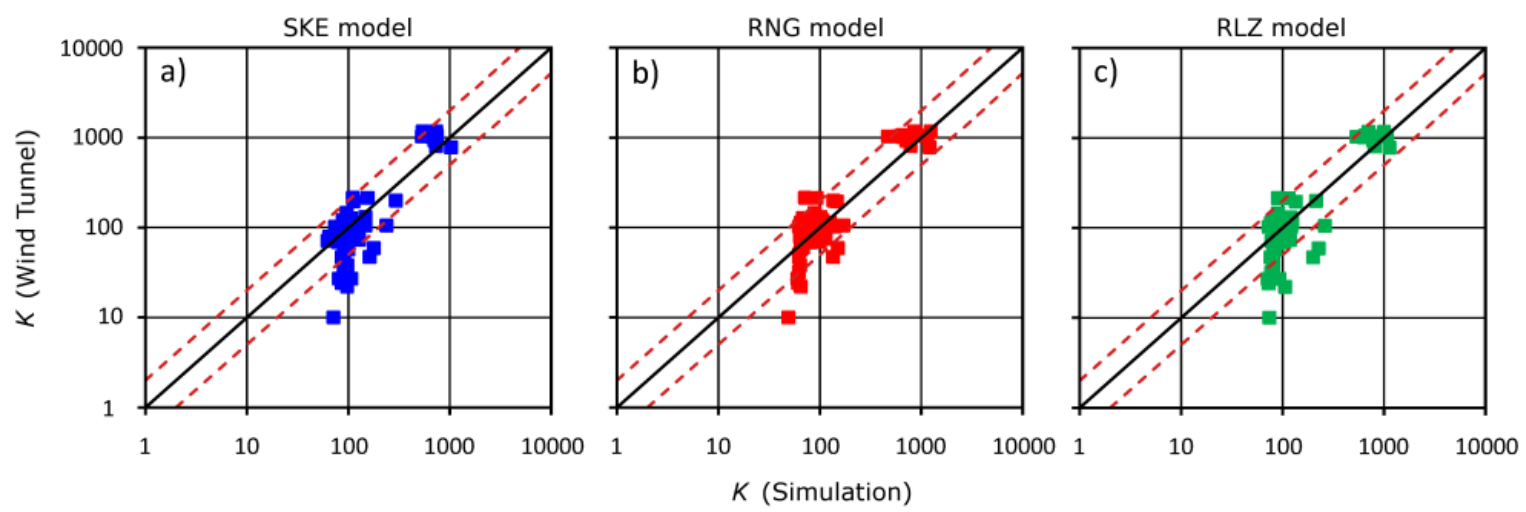

Figure 4: Scatter plots of simulation and wind tunnel $K$ data for stack heights of 1 and $3 \mathrm{~m}$ and momentum ratios of 2.2, 4.5 and 5 obtained with (a) SKE turbulence model, (b) RNG turbulence model and (c) RLZ turbulence model.

\subsection{Average error of sampler concentrations}

Fig. 4 shows the scatter plots for the non-dimensional concentration $K$ values from the wind tunnel measurement and numerical simulations with both stack heights $\left(h_{s}=1\right.$ and $\left.3 \mathrm{~m}\right)$ and various momentum ratios $(M=2.2,4.5$ and 5$)$ for each turbulence model. Eighty percent (80\%) of concentration values were located within a range factor of 2 , as can be seen through points situated between the dashed lines on each side of the median line in Fig. 4a and c, for the SKE and RLZ turbulence models, respectively, whereas in Fig. 4b, the RNG model shows $83 \%$ of $K$ values within this range. The average error, $e_{a}$, for simulated and experimental concentrations obtained with stack heights of 1 and $3 \mathrm{~m}$ (both are momentum ratios for each stack height) and the SKE turbulence model were approximately $50 \%$ and $92 \%$, respectively. Note that the average error was calculated as defined in Lateb et al. (2010a). The corresponding average errors for the RLZ model were smaller than those for the SKE model, i.e., $45 \%$ and $88 \%$. The RNG model remained the best approach for evaluating concentrations with average errors of $38 \%$ and $56 \%$ for stack heights of $1 \mathrm{~m}$ and $3 \mathrm{~m}$, respectively. For the lowest stack height $\left(h_{s}=1 \mathrm{~m}\right)$ and the lowest momentum ratio $(M=2.2)$, the RLZ turbulence model displayed the smallest average error of about $36 \%$. This value was slightly under the values of $37 \%$ and $38 \%$ obtained with the SKE and RNG turbulence models, respectively. In the case of a stack height of $1 \mathrm{~m}$ and a momentum ratio of 5 , the RNG model showed better capability to approach the experimental results, with an average error of $38 \%$ compared to the RLZ and SKE models, which provided $54 \%$ and $63 \%$, respectively. Note that the corresponding correlation coefficients, $\mathrm{R}$, of the concentration dispersion values in Fig. 4, are 0.93, 0.92 and 0.93 for SKE, RNG and RLZ models, respectively.

\subsection{Concentrations on the BE building's roof and the top of the Faubourg tower's leeward wall}

Figs. 5 and 6 show the concentration values obtained using CFD simulations and wind tunnel experiments for the lower stack height $\left(h_{s}=1 \mathrm{~m}\right)$ and the higher stack height $\left(h_{s}=3 \mathrm{~m}\right)$, respectively. Two momentum ratios are shown in each figure. The non-dimensional concentration $K$ values obtained using numerical simulations and wind tunnel experiments are displayed for each sampler location. The analysis of these results will be discussed separately for the BE building's roof and the Faubourg tower's leeward wall. Afterwards, a general tendency will be expressed. 

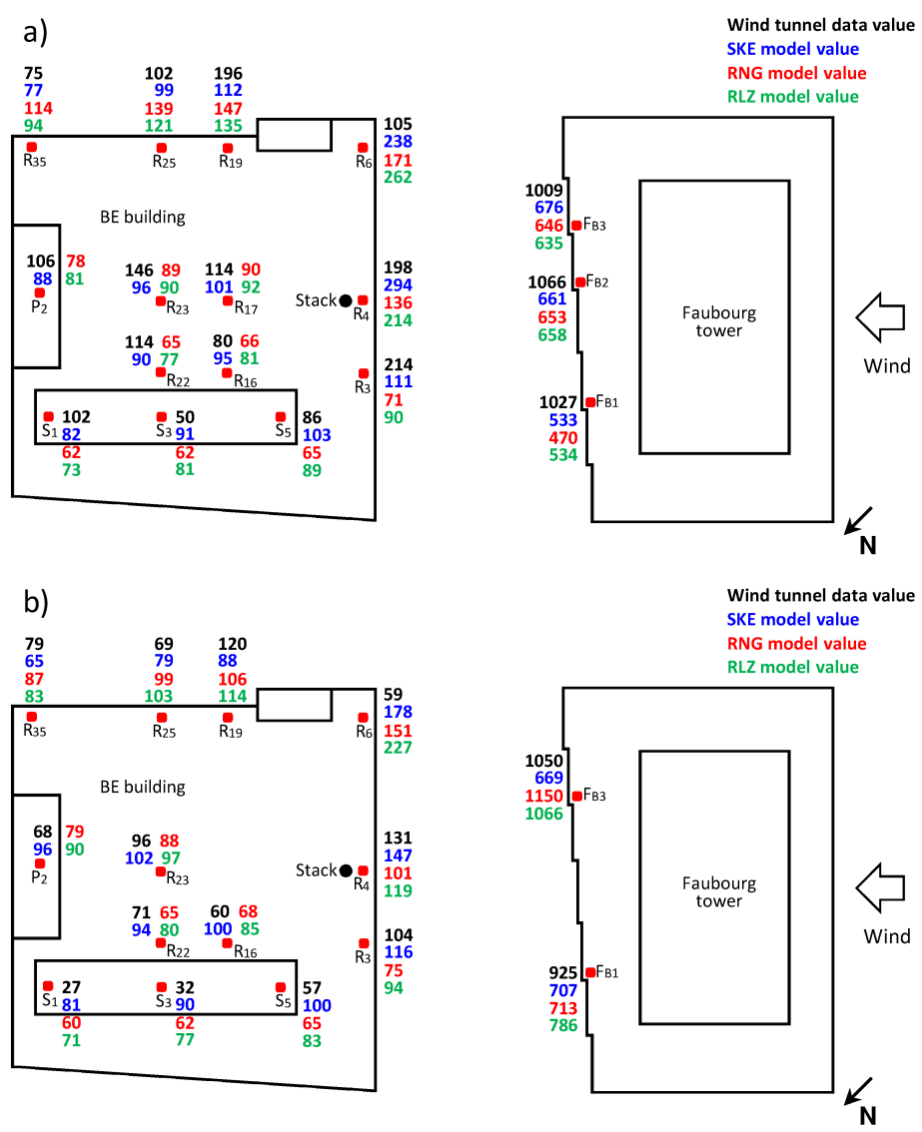

Figure 5: Simulation and wind tunnel values of $K$ for a stack height, $h_{s}$, of 1 metre with (a) $M=2.2$ and (b) $M=5$.

\subsubsection{On the BE building's roof}

The SKE turbulence model showed an underestimation of the concentration in the central and southeast part of the roof for both stack heights using the lower momentum ratio $(M=2.2)$. The increase in momentum ratio revealed an opposite tendency (an overestimation) in the centre, while the same tendency (an underestimation) was still roughly observed in the southeast part of the roof. Major overestimations were noted at samplers located in the windward and northwest parts of the BE building's roof for all the cases studied.

The RNG model also underestimated concentrations in nearly all parts of the roof for both stack heights with the lower momentum ratio. Only a few samplers located near the perimeter of the roof were overestimated $\left(R_{5}, R_{6}, R_{14}\right.$, and $\left.R_{25}\right)$. The tendency was reversed for a few samplers in the centre with the increase of momentum ratio: numerical values overestimated the experimental ones. The underestimation persisted in the central and upwind parts of the roof for the case using $h_{s}=1 \mathrm{~m}$ and $M=5$. For higher stack heights and momentum ratios $\left(h_{s}=3 \mathrm{~m}\right.$ and $\left.M=4.5\right)$, the simulations agreed relatively well with the experimental results in the centre of the roof. Underestimation was observed, however, for all cases at sampler $\mathrm{R}_{4}$, near the stack. The overestimation observed in the side parts with $h_{s}=1 \mathrm{~m}$ and $M=5$ were still noticeable at the highest stack $\left(h_{s}=3 \mathrm{~m}\right)$. 

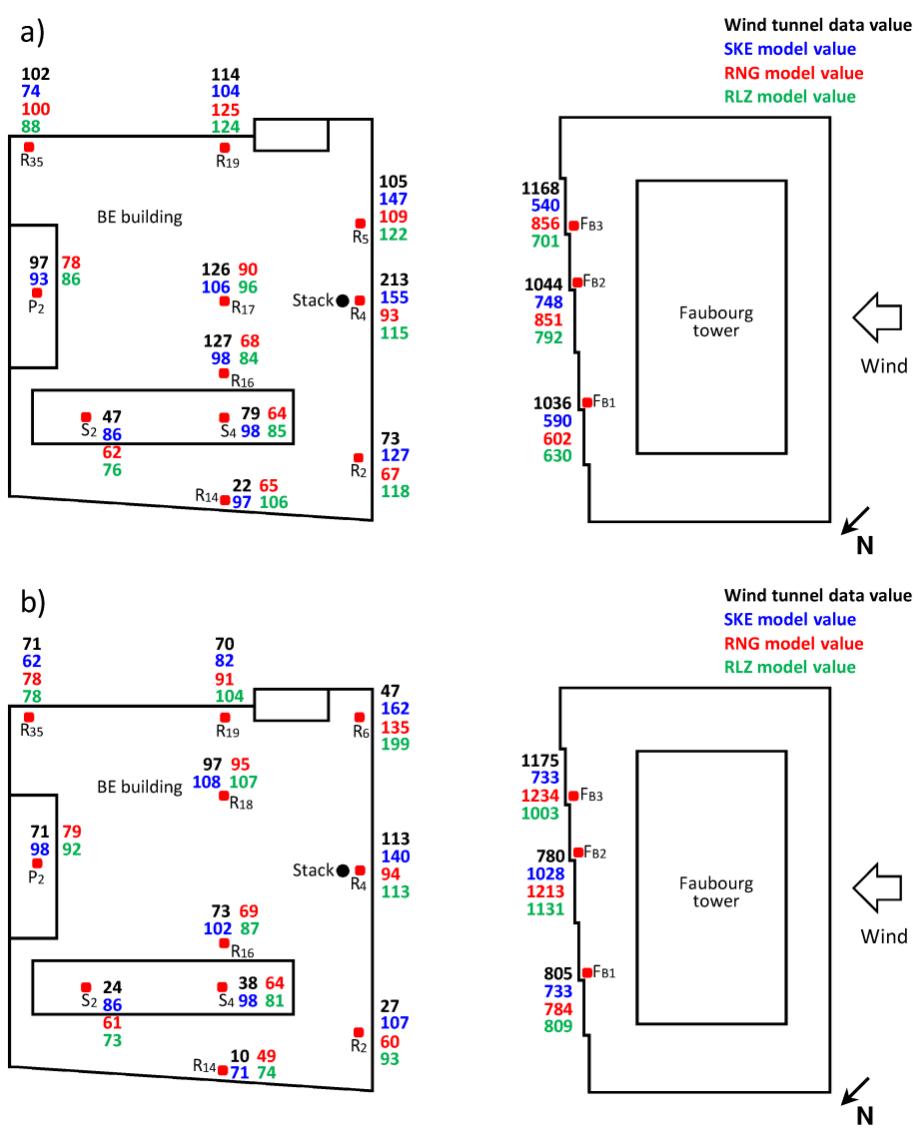

Figure 6: Simulation and wind tunnel values of $K$ for a stack height, $h_{s}$, of 3 metres with (a) $M=2.2$ and (b) $M=4.5$.

The RLZ turbulence model showed under- and overestimation on the BE building's roof for both stack heights $\left(h_{s}=1\right.$ and $\left.3 \mathrm{~m}\right)$ using the lowest momentum ratio $(M=2.2)$. For the smaller stack height, an overestimation was observed at many samplers located along the perimeter of the roof. At the roof's centre, an underestimation of concentrations was observed and only a few samplers saw their concentration tendencies reversed along with increasing stack height $\left(h_{s}=3 \mathrm{~m}\right)$. For higher pollutant exhaust velocities, the concentrations of the roof samplers increased surpassing the experimental values. Only two of the three samplers located near the upwind edge of the roof remained underestimated: $h_{s}=1 \mathrm{~m}$ and $M=5$. At the farthest sampler towards the southeast side, $\mathrm{R}_{6}$, an overestimation of $K$ remained.

\subsubsection{On the top of the Faubourg tower's leeward wall}

The results obtained for all the turbulence models underestimated the concentration $K$ on the Faubourg tower's leeward wall, with a lower momentum ratio for both stack heights. Increasing the exhaust velocity did not significantly change the SKE turbulence model: the underestimation remained, except at the sampler in the centre, $\mathrm{F}_{B 2}$, and for the highest stack $\left(h_{s}=3 \mathrm{~m}\right)$. For the RNG model, the computed concentration was greater than the experimental value for the higher pollutant velocity at sampler $\mathrm{F}_{B 3}$, whereas an underestimation was observed at sampler $\mathrm{F}_{B 1}$. All $K$ values obtained using the RLZ model underestimated the experimental results for $M=2.2$ and both stack heights, whereas with the highest pollutant velocities, the RLZ model showed an overestimation at almost all samplers except for $\mathrm{F}_{B 1}$ and $\mathrm{F}_{B 3}$, where $K$ was underestimated for $h_{s}$ of 1 and $3 \mathrm{~m}$, respectively. 


\subsection{Variation of $K$ along the stack axis on the BE building's roof}

Fig. 7a and b shows the evolution of concentrations $K$ for momentum ratios of 2.2 and 5 , respectively, with a stack height of 1 metre at samplers $\mathrm{R}_{4}, \mathrm{R}_{23}$ and $\mathrm{P}_{2}$ located at the stack axis on the BE building's roof. For both momentum ratios, the RLZ model provided the best concentration value at sampler $\mathrm{R}_{4}$ near the stack, compared to those obtained with SKE and RNG models. All models showed slight differences between their results for the higher momentum ratio. For the lower value of $M$, however, discrepancies were clearly noticeable at sampler, $\mathrm{R}_{4}$, near the stack. The RNG model underestimated the $K$ value within $30 \%$, while the SKE model provided an overestimation of $48 \%$. Far downstream of the stack, agreement between the simulated concentration values and experimental values was better. The RLZ model seemed to provide more accurate concentration values at samplers close to the stack, as compared to the SKE and RNG models.
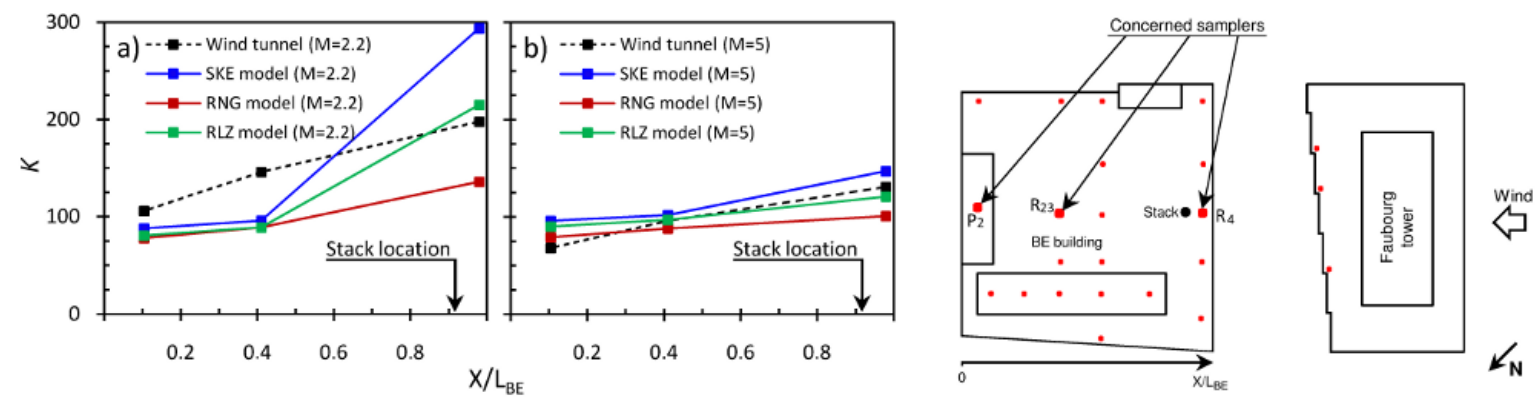

Figure 7: Measured and calculated variation of $K$ at samplers $\mathrm{R}_{4}, \mathrm{R}_{23}$ and $\mathrm{P}_{2}$ along the $x$ axis on $\mathrm{BE}$ roof with $h_{s}=1$ m and for momentum ratios of (a) $M=2.2$ and (b) $M=5$.

\subsection{Concentrations along the Faubourg tower's leeward wall}

Fig. 8 shows the vertical evolution of the measured and simulated concentrations along the leeward wall of the Faubourg tower. All the turbulence models used overestimated the experimental values and displayed approximately the same concentration values at the samplers located at the higher level of the tower's leeward wall and at the BE building's roof level. Discrepancies between the numerical and experimental values were greater at the building roof level. At mid-height on the Faubourg tower, the SKE model predicted a more accurate $K$ value, whereas the RLZ model showed an inadequate result. Although none of the turbulence models tested reproduced the concentration trend in the upper region between the two buildings, the RLZ model remained the only one to reproduce the trend slope in the lower region. This seems to indicate that the RLZ model correctly reproduced pollutant distribution in that lower region.
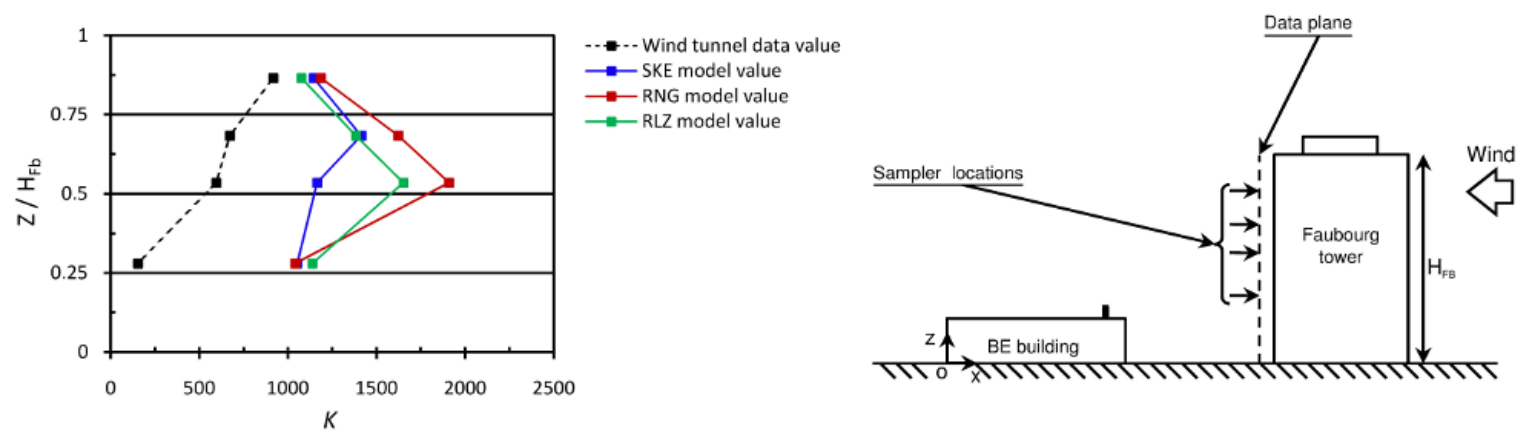

Figure 8: Vertical profiles of $K$ on the leeward wall of the Faubourg tower (Wind tunnel and simulation 1:200 scale values, $M=4.5$ and $h_{s}=3 \mathrm{~m}$ ). 


\subsection{Variation of $K$ at specified samplers for different stack heights}

Fig. 9 shows the dependence of concentration on stack height at different samplers located on the BE building's roof and on the Faubourg tower's leeward wall. For the BE building's roof, the samplers are those located along the stack axis, i.e., $\mathrm{R}_{4}, \mathrm{R}_{17}$ and $\mathrm{P}_{2}$, and those on the tower's leeward wall are $\mathrm{F}_{B 1}, \mathrm{~F}_{B 2}$ and $\mathrm{F}_{B 3}$. At sampler $\mathrm{R}_{4}$, near the stack, the RLZ model provided the best overall agreement with the wind tunnel results: a slight overestimation of $K$ was noted for the lower stack height $\left(h_{s}=1\right.$ $\mathrm{m})$, whereas for higher stack heights $\left(h_{s}=4\right.$ and $\left.7.2 \mathrm{~m}\right)$, very good agreement was observed. For a stack height of $3 \mathrm{~m}$, the SKE model provided the best approach. The RNG model underestimated $K$ values for all stack heights, with less discrepancy for $h_{s}$ of 4 and $7.2 \mathrm{~m}$. In the central and the leeward parts of the roof, represented by samplers $R_{17}$ and $P_{2}$ shown in Fig. $9 b$ and c, respectively, all models provided roughly the same results and the same trend. The concentrations obtained remained constant with increasing stack height, whereas a decrease of $K$ was noted in the experimental values.

On the Faubourg tower's leeward wall, the trend of the experimental concentrations was the same for all three samplers. $K$ concentration increased between stack heights of 1 and $3 \mathrm{~m}$, except at sampler $\mathrm{F}_{B 2}$, where a constant trend was noted; afterwards, $K$ decreased for the remaining stack heights, with an abrupt decrease between stack heights of 3 and 5 metres. The simulated concentration trend was showed a slight increase for all models tested at samplers $\mathrm{F}_{B 1}$ and $\mathrm{F}_{B 2}$, with a strong underestimation of $K$ at the lowest stack height $\left(h_{s}=1 \mathrm{~m}\right)$, and an overestimation for the highest stack height $\left(h_{s}=7.2\right.$ $\mathrm{m})$. All the models provided roughly the same results at sampler $\mathrm{F}_{B 1}$, and better agreement between the numerical and the experimental values of $K$ was found at the 4-metre stack. At sampler $\mathrm{F}_{B 3}$, the RLZ and RNG turbulence models showed the same evolution as for samplers $\mathrm{F}_{B 1}$ and $\mathrm{F}_{B 2}$, while the SKE model systematically underestimated $K$ for all stack heights. The SKE model seemed to be the best model for $h_{s}=7.2 \mathrm{~m}$ at sampler $\mathrm{F}_{B 3}$, whereas the RNG and RLZ models displayed improved prediction using a stack height of $4 \mathrm{~m}$.
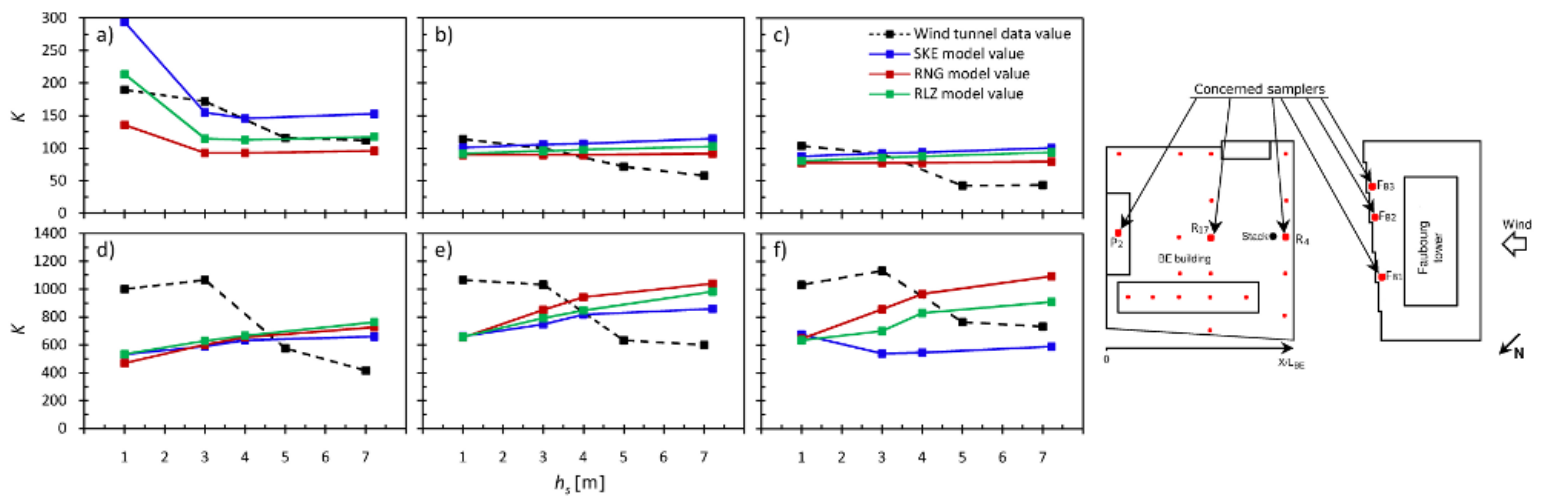

Figure 9: Measured and calculated concentrations $K$ for $M=2.2$ and for different stack heights, $h_{s}$, at samplers (a) $\mathrm{R}_{4}$, (b) $R_{17}$, (c) $P_{2}$, (d) $F_{B 1}$, (e) $F_{B 2}$ and (f) $F_{B 3}$.

\section{Discussion}

The average errors for the numerical concentrations as compared to the experimental measurements indicate that the RNG turbulence model reproduced better concentration for stack heights of 1 and 3 $\mathrm{m}$, with greater momentum ratios $(M=5$ and 4.5$)$. The RLZ model showed the best agreement with experimental results for the smallest stack $\left(h_{s}=1 \mathrm{~m}\right)$ using the lower momentum ratio $(M=2.2)$. For this case $\left(h_{s}=1 \mathrm{~m}\right.$ and $\left.M=2.2\right)$, the RNG and SKE models showed similar levels in averaged error $\left(e_{a}\right)$ values, compared to the RLZ model. Significant discrepancies in $e_{a}$ values were observed mainly for higher stack heights, and greater momentum ratios for the three turbulence models tested, and the largest $e_{a}$ values were observed with the SKE model. Given the well-known problems of SKE models in reproducing the basic flow structure around a building, and since the prediction accuracy of dispersion 
is strongly related to the simulated flow field, as stated by Tominaga and Stathopoulos (2009), the inaccuracy of the SKE model was expected, even more so with higher pollutant velocities, where strong interactions occurred above the stack, between the wind flow and the exhausted pollutant.

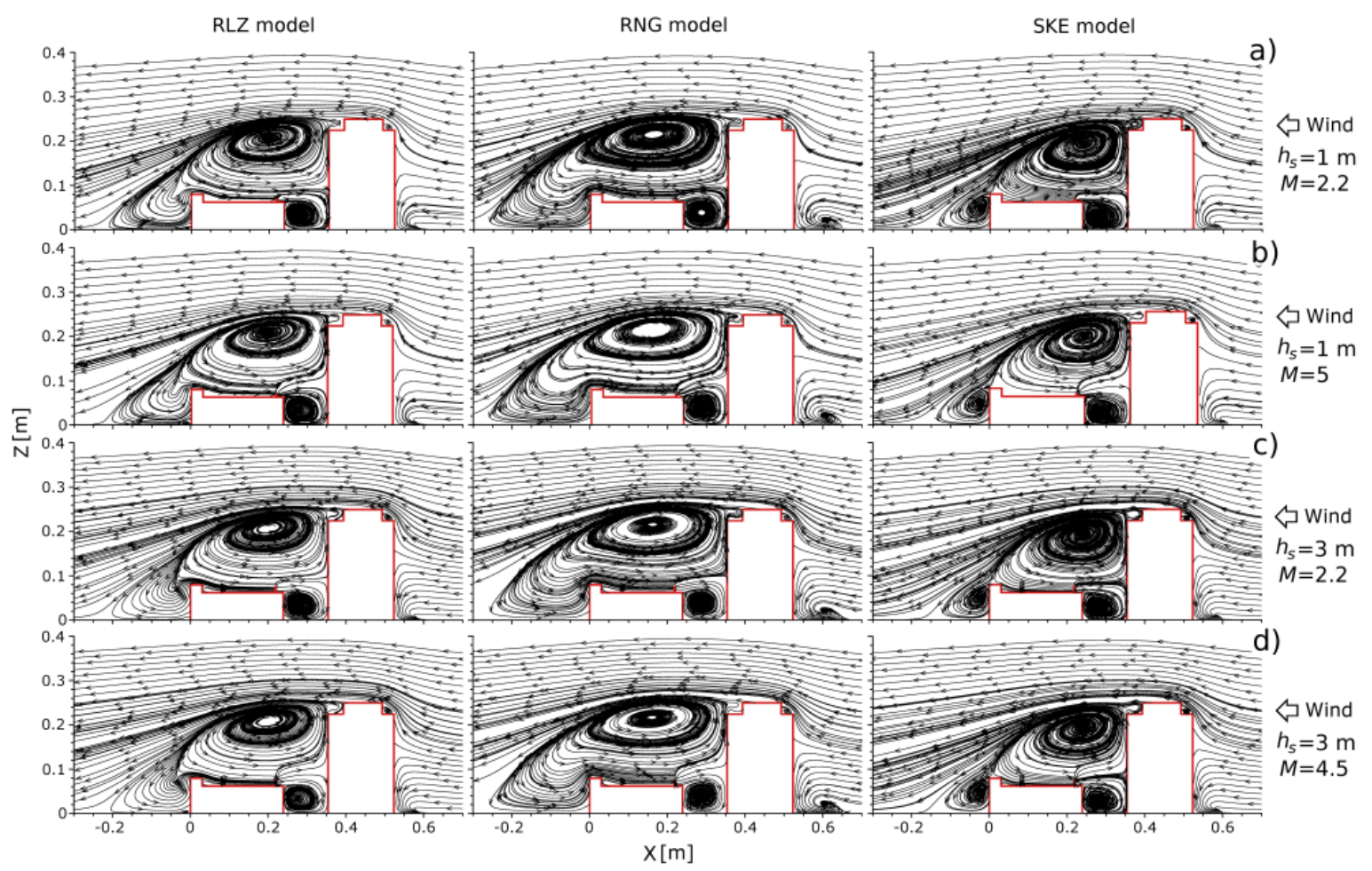

Figure 10: Streamlines on the vertical $(x-z)$ plane through stack position $(y=0.0155 \mathrm{~m})$ for $(\mathrm{a}) h_{s}=1 \mathrm{~m}$ and $M=2.2$, (b) $h_{s}=1 \mathrm{~m}$ and $M=5$, (c) $h_{s}=3 \mathrm{~m}$ and $M=2.2$ and (d) $h_{s}=3 \mathrm{~m}$ and $M=4.5$. Columns from left to right represent results for RLZ, RNG and SKE models, respectively.

The behaviour of the flow field in the vertical cross-section at the stack position $(y=0.0155 \mathrm{~m})$ is shown in Fig. 10 for two momentum ratios with stack heights of 1 and $3 \mathrm{~m}$. The significant underestimation obtained at most samplers on the BE building's roof and the tower's leeward wall, for both stack heights $\left(h_{s}=1\right.$ and $\left.3 \mathrm{~m}\right)$ and the lowest momentum ratio $(M=2.2)$, was due to the pollutant, which was directed at the lower region between the two buildings, as shown in Fig. 10a and $\mathrm{c}$ for all the turbulence models used. This behaviour also explains the underestimated concentrations obtained at samplers located at higher levels, i.e., $\mathrm{F}_{B 1}, \mathrm{~F}_{B 2}$ and $\mathrm{F}_{B 3}$. For higher exhaust velocities, the pollutant rose towards the upper region between the two buildings and reached the tower roof, as shown in Fig. 10b and d; consequently, an overestimation of the concentration was observed at sampler $\mathrm{F}_{B 2}$, as shown in Fig. 6b, and at samplers located along the tower's leeward wall, as indicated in Fig. 8. This was predictable, since none of the turbulence models tested was able to reproduce the upper region between the two buildings, as stated previously in Fig. 8. 


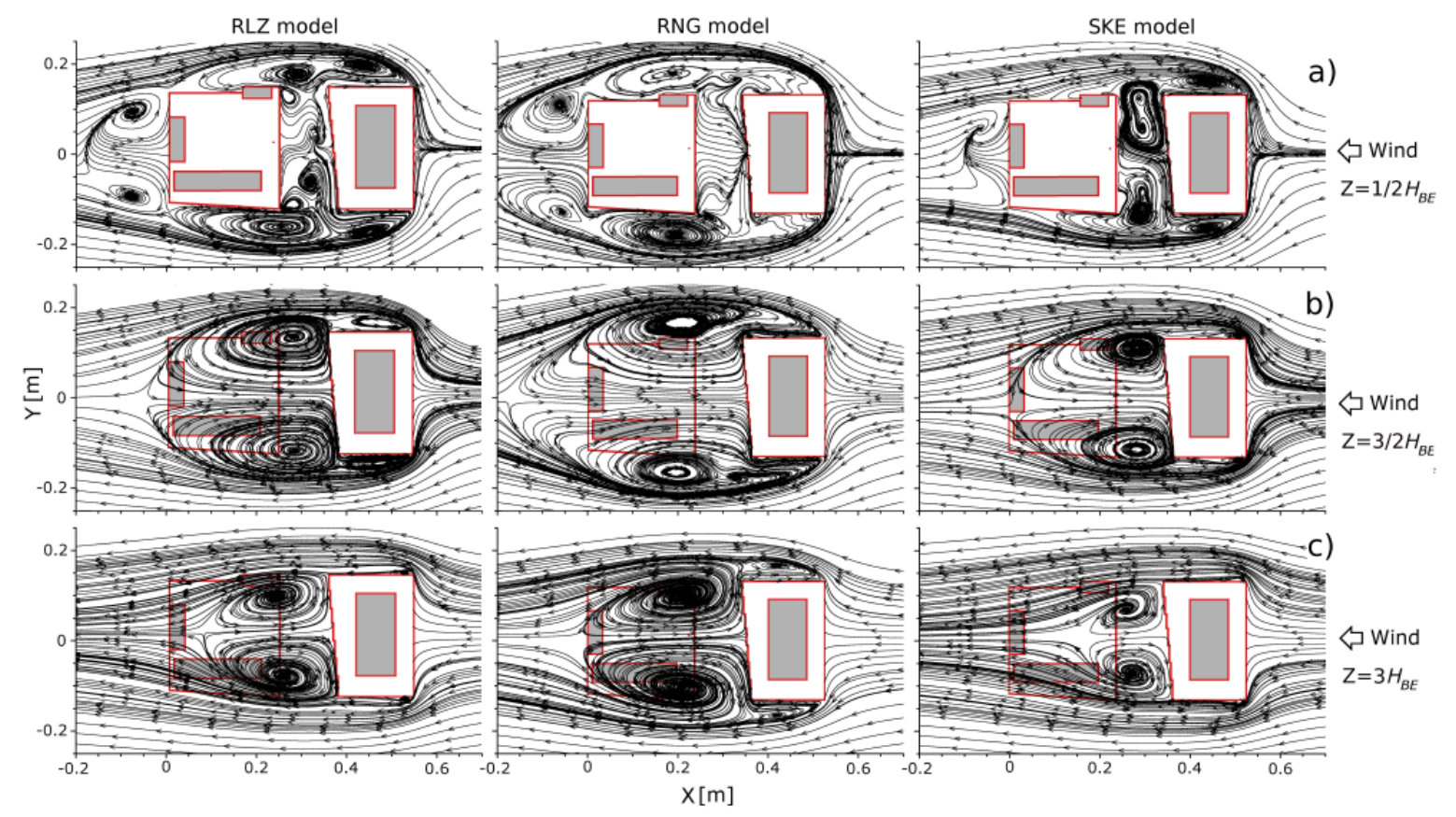

Figure 11: Streamlines on the horizontal $(x-y)$ plane at different vertical positions for case $h_{s}=1 \mathrm{~m}$ and $M=5$. Columns from left to right represent the results of RLZ, RNG and SKE models, respectively, at height (a) $1 / 2 H_{B E}$, (b) $3 / 2 H_{B E}$ and (c) $3 H_{B E}$ from the ground.

The well-established airflow pattern around a building, as reported by authors such as Rodi (1997); Blocken et al. (2011); and ASHRAE (2009), induces a horseshoe vortex system at the ground level of a building's upwind facade. This phenomenon seems to be better represented by the RNG turbulence model, as compared to the SKE and RLZ models, each of which displays a very small vortex at the tower's upwind wall, as shown in Fig. 10. The flow structure in the horizontal plane $(x-y)$ at different levels from the ground (i.e., height levels of $1 / 2 H_{B E}, 3 / 2 H_{B E}$ and $3 H_{B E}$ ) for the three turbulence models is depicted in Fig. 11. The flow field shows strong curvatures and recirculation zones around the two-building configuration, particularly at the lower region, as shown in Fig. 11a. This lower region shows a complex separated flow for the RLZ turbulence model, whereas the SKE model shows a configuration with a clear generation of two main vortices spread out over each side, between the tower and the building. For the RNG model, the recirculation fluxes seem to occur mainly in the vertical plane. In the BE building's wake, two horizontal vortices occur with the RLZ and RNG turbulence models; however, the only vortex displayed by the SKE model seems to be occurring in the vertical plane. For higher levels, as indicated in Fig. 11b, the streamlines skirt the tower along its sides and display two wide main recirculation zones in the tower's wake. These zones, which are less significant for the SKE model when compared to RLZ and RNG models, become even smaller as one moves towards the upper levels, as shown in Fig. 11c.

Fig. 12 shows the ways in which turbulent kinetic energy $k$ is distributed over the vertical crosssection at the centre of the domain $(y=0 \mathrm{~m})$, obtained using the turbulence models tested for $h_{s}=1$ $\mathrm{m}$ and $M=5$. As can be seen at the Faubourg tower's upstream corner, the highest turbulent kinetic energy iso-contour value is obtained with the SKE turbulence model. The maximum values for $k$ produced by the SKE model are $13 \%$ and $46 \%$ higher, compared to those obtained with RLZ and RNG models, respectively.

This high production of $k$, as stated by several authors (e.g., Murakami, 1993; Rodi, 1997; Murakami, 1998; Wright and Easom, 2003; Tominaga et al., 2008), is a well-known shortcoming of the SKE model, which induces inaccurate wind-flow patterns. According to some of these authors (Mu- 
rakami, 1993; Rodi, 1997; Wright and Easom, 2003), this excessive $k$-production takes its origin from isotropic turbulent viscosity formulation.

According to Wright and Easom (2003), the wake region exhibits strong turbulence anisotropy where the lateral Reynolds stress component, $\overline{u_{2} u_{2}}$, dominates; the inability of the isotropic turbulent viscosity models to correctly simulate the difference between Reynolds normal stresses produces an underprediction of the lateral Reynolds stresses. Moreover, Nallasamy (1987) has stressed the assumption of isotropic turbulent viscosity as the main practical limitation of the two equation models; Pope (2000) has noted that the assumption of the turbulent viscosity hypothesis is more reasonable in cases where the mean velocity gradients and turbulence characteristics evolve slowly, following the mean flow. For this reason, since the distribution of the mean velocity gradients varies significantly; since it is dependent upon its relative position over the configuration (Murakami, 1993), and since it is directly related to the Reynolds stress components, the complex flow field around this two-building configuration may be poorly reproduced using two equation $k-\epsilon$ models. In addition, the flow field around the configuration under study is characterized by vortex shedding from the tower's leeward sides and roof, which generate a strong degree of unsteadiness and periodic fluctuation. On the one hand, turbulence dispersion is the dominant mechanism for particle spread (Canepa, 2004) and cannot be predicted accurately by assuming a steady-state process (Chang and Meroney, 2003). On the other hand, when using steady-state models, Rodi (1997) has emphasized a severe underprediction of turbulence fluctuations in the wake region, and Shirasawa et al. (2008) have found that turbulent diffusion flux was insufficiently spread in lateral directions. Consequently, the steady state of the tested models is probably an additional weakness that contributes to inaccuracy regarding the flow and dispersion fields.

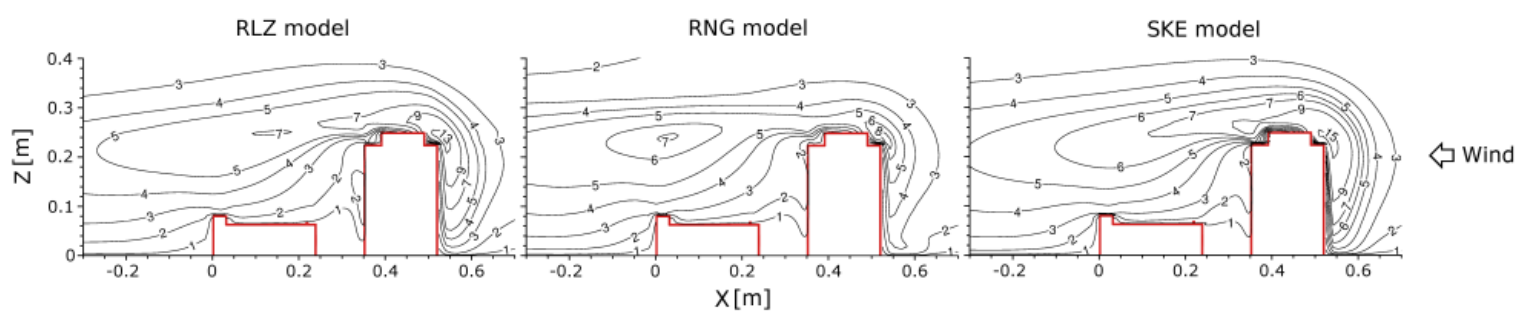

Figure 12: Distribution of turbulent kinetic energy $k$ in $\left[\mathrm{m}^{2} \mathrm{~s}^{-2}\right]$, on the vertical $(x-z)$ plane through the centre of the domain $(y=0 \mathrm{~m})$, obtained with RLZ, RNG and SKE turbulence models for case $h_{s}=1 \mathrm{~m}$ and $M=5$.

Fig. 13 shows the distribution of the non-dimensional Reynolds stress components (i.e., $\overline{u_{1}^{2}} / 2 k$, $\overline{u_{2}^{2}} / 2 k, \overline{u_{3}^{2}} / 2 k$ and $\left.\left|\overline{u_{1} u_{3}} / 2 k\right|\right)$ and the turbulent viscosity, $\nu_{t}$, in the vertical cross-section $(y=0 \mathrm{~m})$ for $h_{s}=1 \mathrm{~m}$ and $M=5$. According to Shih et al. (1995b), the "realizability" condition imposes as requirement (i) the non-negativity of each Reynolds normal stress $\left(0 \leq \overline{u_{\alpha}^{2}}\right)$, and (ii) Schwarz's inequality $\left({\overline{u_{\alpha} u_{\beta}}}^{2} / \overline{u_{\alpha}^{2}} \overline{u_{\beta}^{2}} \leq 1\right)$ between any fluctuating quantities in the entire computational domain, to prevent the flow field from reproducing non-physical results. Using the turbulent kinetic energy expression Eq. (5), both requirements can be written in non-dimensional form as $0 \leq \overline{u_{\alpha}^{2}} / 2 k \leq 1$ (non-negativity condition) and $0 \leq\left|\overline{u_{\alpha} u_{\beta}} / 2 k\right| \leq 1$ (Schwarz's inequality condition). Throughout Fig. 13 , only the SKE model fails to respect the realizability criterion, due to the negative values found at the upper region of the tower's windward wall, as shown in Fig. 13c. The region of concern is located in the upper region of the stagnation point, which occurs on the tower's windward facade and whence the wind flow is deviated and accelerated to the upward, downward and sideward zones, inducing strong velocity gradients along the vertical and lateral directions. Therefore, the negative values of vertical Reynolds normal stress are mainly due to the great local mean velocity gradients, $\partial U_{3} / \partial z$, in the vertical direction, since the displayed values of turbulent viscosity $\nu_{t}$, in that region are not very significant, as illustrated in Fig. 13e of the SKE model. However, Schwarz's inequality condition is rigorously respected by all the tested models, as shown in Fig. 13d. 


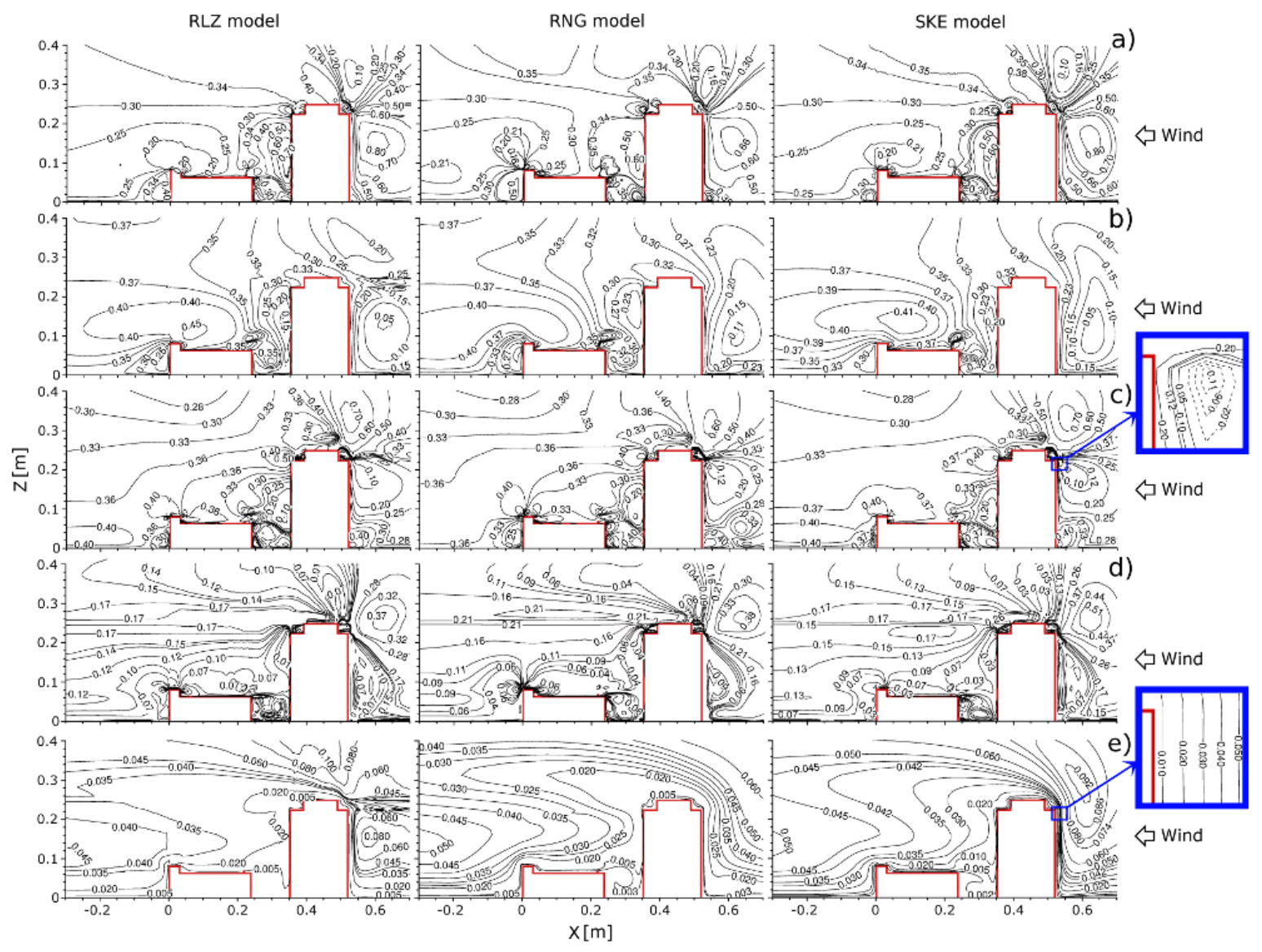

Figure 13: Distribution on the vertical $(x-z)$ plane through the centre of the domain $(y=0 \mathrm{~m})$ for case $h_{s}=1 \mathrm{~m}$ and $M=5$ of the non-dimensional Reynolds stress components (a) $\overline{u_{1}^{2}} / 2 k$, (b) $\overline{u_{2}^{2}} / 2 k$, (c) $\overline{u_{3}^{2}} / 2 k$, (d) $\left|\overline{u_{1} u_{3}} / 2 k\right|$ and (e) turbulent viscosity $\nu_{t}$ in $\left[\mathrm{m}^{2} \mathrm{~s}^{-1}\right]$. Columns from left to right represent the results of RLZ, RNG and SKE models, respectively. Dashed lines indicate negative values.

To ensure that the requirement of realizability is respected throughout the computational domain, other critical planes were analyzed. These included the horizontal plane at the stagnation point and the vertical plane passing by the stack position, since strong interactions occurred between the emitted pollutant and the wind flow above the stack exit. The same anomaly was observed with the SKE model: negative values of vertical Reynolds normal stress, in the vertical plane passing by the stack, due to strong velocity gradients. The SKE turbulence model was the only model to produce non-physical values in the computed results, whereas the other models, i.e., RLZ and RNG models, appear to have rigorously respected the physical principle of the realizability requirement.

The significant underestimation of concentration $K$ obtained at most sampler locations on the BE building's roof and at the top of the Faubourg tower's leeward wall, with lowest momentum ratio $(M=2.2)$ and both stack heights $\left(h_{s}=1\right.$ and $\left.3 \mathrm{~m}\right)$, as stated previously in Figs. 5a and 6a, is probably due to a lack of lateral dispersion. To promote the plume dispersion artificially, various turbulent Schmidt numbers representing the ratio of turbulent viscosity to turbulent mass diffusivity $\left(S c_{t}=\nu_{t} / D_{t}\right)$ were tested, as suggested by Lateb et al. (2010b). Various low $S c_{t}$ values (0.1, 0.3 and 0.5 ), compared to the commonly used number 0.7 , were tested in order to favour turbulent mass diffusivity, $D_{t}$, against turbulent viscosity $\nu_{t}$ (not reported here, for the sake of brevity). Only the SKE and RLZ models were tested, since the RNG model does not allow a modification in the $S c_{t}$ value when using Fluent. Surprisingly, the results obtained showed no significant changes in concentration values, in contrast to some previous studies (Tominaga and Stathopoulos, 2007; Blocken et al., 2008; Tominaga 
and Stathopoulos, 2009; Gousseau et al., 2011a; Chavez et al., 2011) which showed an influence of $S c_{t}$ on the concentration distributions when it is question of a single building. Notwithstanding, Chavez et al. (2011) concluded that the changes in $S c_{t}$ do not have a major impact on pollutant dispersion in the presence of adjacent buildings, which is the case in this study. In addition, $S c_{t}$ varies with different dispersion problems and flow structures (Hang et al., 2012) and a change of turbulent Schmidt number influences only the diffusion mechanism and not the fluid dynamics (Di-Sabatino et al., 2007). Finally, the dispersion process is probably dominated by the advection transport phenomenon since it cannot be compensated by promoting the dispersion through low $S c_{t}$ values in this case of a complex flow field where strong separation/recirculation zones occur. Therefore, the turbulent diffusion mechanism which seems insignificant - in the wake region where most of all samplers are located - can be a consequence of a high underestimation of Reynolds normal stress components and the steady-state methodology.

\section{Summary and conclusions}

Pollutant dispersion in a two-building configuration was investigated using various RANS turbulence $k-\epsilon$ models (a standard $k-\epsilon$ model, a RNG $k-\epsilon$ model and a realizable $k-\epsilon$ model) in order to determine the best turbulence model to reproduce pollutant plume dispersion. It was found that the realizable turbulent $k-\epsilon$ model yielded the best agreement with wind tunnel experimental data for the lower stack height and momentum ratio, while the RNG turbulence model performed best for the higher stack height and both momentum ratios. Despite an overestimation of $K$ using the RLZ model for higher momentum ratios, this model is the only one that provided the correct trend for concentration distribution in the lower region between the two buildings. Given the well-known problems of the SKE model in reproducing flow-field structures around buildings, this model was generally found to be inadequate for reproducing vertical concentration distribution, and was the only turbulence model that failed to satisfy the realizability requirement, consequently producing non-physical results. For the simulated complex flow fields where strong separation/recirculation zones occur, the dispersion process is probably dominated by the advection transport phenomenon and cannot be compensated by promoting the turbulent diffusion process through low turbulent Schmidt number values: the incorrect estimation of the Reynolds normal stresses and the steady-state assumption of the turbulence models tested are thought to be the main sources of the insignificant turbulent diffusivity stated in the wake region, therefore the origin of the lack of lateral dispersion previously observed. It is recommended that an attempt be made to use unsteady turbulence models in order to shed light on the effects of steadiness on both the dispersion process and flow-field structure.

\section{Acknowledgements}

Financial support for this study from the Fonds Québécois de la Recherche sur la Nature et les Technologies (FQRNT) is gratefully acknowledged. The authors thank the anonymous reviewers for thoroughly reading the manuscript and for their valuable comments. The authors are grateful to Professor Bert Blocken, member of the journal's Editorial Board, who agreed to be Acting Editor and handled the review process for this paper, since the Editor is a co-author. The review was carried out outside the Elsevier Editorial System (EES) to ensure the anonymity of the reviewers.

\section{References}

ASHRAE, 2007. Chapter 44: Building air intake and exhaust design. In: ASHRAE Handbook Heating, Ventilating, and Air-Conditioning Applications. American Society of Heating, Refrigerating and Air-conditioning Engineers, Atlanta, USA.

ASHRAE, 2009. Chapter 24: Airflow around buildings. In: ASHRAE Handbook - Fundamentals. American Society of Heating, Refrigerating and Air-conditioning Engineers, Atlanta, USA. 
ASHRAE, 2011. Chapter 45: Building air intake and exhaust design. In: ASHRAE Handbook Fundamentals. American Society of Heating, Refrigerating and Air-conditioning Engineers, Atlanta, USA.

Assimakopoulos, V. D., ApSimon, H. M., Moussiopoulos, N., 2003. A numerical study of atmospheric pollutant dispersion in different two-dimensional street canyon configurations. Atmospheric Environment 37 (29), 4037-4049.

Blocken, B., Stathopoulos, T., Carmeliet, J., 2007. CFD simulation of the atmospheric boundary layer: Wall function problems. Atmospheric Environment 41 (2), 238-252.

Blocken, B., Stathopoulos, T., Carmeliet, J., Hensen, J. L. M., 2011. Application of computational fluid dynamics in building performance simulation for the outdoor environment: an overview. Journal of Building Performance Simulation 4 (2), 157-184.

Blocken, B., Stathopoulos, T., Saathoff, P., Wang, X., 2008. Numerical evaluation of pollutant dispersion in the built environment: Comparisons between models and experiments. Journal of Wind Engineering and Industrial Aerodynamics 96 (10-11), 1817-1831.

Canepa, E., 2004. An overview about the study of downwash effects on disperson of airborne pollutants. Environmental Modelling \& Software 19 (12), 1077-1087.

Celik, I. B., Ghia, U., Roache, P. J., Freitas, C. J., Coleman, H., Raad, P. E., 2008. Procedure for estimation and reporting of uncertainty due to discretization in CFD applications. Journal of Fluids Engineering 130 (078001), 1-4.

Chang, C. H., Meroney, R. N., 2003. Concentration and flow distributions in urban street canyons: wind tunnel and computational data. Journal of Wind Engineering and Industrial Aerodynamics 91 (9), 1141-1154.

Chavez, M., Hajra, B., Stathopoulos, T., Bahloul, A., 2011. Near-field pollutant dispersion in the built environment by CFD and wind tunnel simulations. Journal of Wind Engineering and Industrial Aerodynamics 99 (4), 330-339.

Contini, D., Cesari, D., Donateo, A., Robins, A. G., 2009. Effects of reynolds number on stack plume trajectories simulated with small scale models in a wind tunnel. Journal of Wind Engineering and Industrial Aerodynamics 97 (9-10), 468-474.

Di-Sabatino, S., Buccolieri, R., Pulvirenti, B., Britter, R., 2007. Simulations of pollutant dispersion within idealised urban-type geometries with CFD and integral models. Atmospheric Environment 41 (37), 8316-8329.

Franke, J., Hellsten, A., Schlünzen, H., Carissimo, B., 2007. Best practice guideline for the CFD simulation of flows in the urban environment. Cost Action 732.

Gomes, M. S. P., Isnard, A. A., Pinto, J. M. C., 2007. Wind tunnel investigation on the retention of air pollutants in three-dimensional recirculation zones in urban areas. Atmospheric Environment 41 (23), 4949-4961.

Gousseau, P., Blocken, B., Stathopoulos, T., van Heijst, G. J. F., 2011a. CFD simulation of near-field pollutant dispersion on a high-resolution grid: A case study by LES and RANS for a building group in downtown Montreal. Atmospheric Environment 45 (2), 428-438.

Gousseau, P., Blocken, B., van Heijst, G. J. F., 2011b. CFD simulation of pollutant dispersion around isolated buildings: On the role of convective and turbulent mass fluxes in the prediction accuracy. Journal of Hazardous Materials 194, 422-434. 
Hajra, B., Stathopoulos, T., 2012. A wind tunnel study of the effect of downstream buildings on near-field pollutant dispersion. Building and Environment 52, 19-31.

Hajra, B., Stathopoulos, T., Bahloul, A., 2011. The effect of upstream buildings on near-field pollutant dispersion in the built environment. Atmospheric Environment 45, 4930-4940.

Hang, J., Li, Y., Sandberg, M., Buccolieri, R., Di-Sabatino, S., 2012. The influence of building height variability on pollutant dispersion and pedestrian ventilation in idealized high-rise urban areas. Building and Environment 56, 346-360.

Hefny, M., Ooka, R., 2009. CFD analysis of pollutant dispersion around buildings: Effect of cell geometry. Building and Environment 44 (8), 1699-1706.

Huang, M. F., Lau, I. W. H., Chan, C. M., Kwok, K. C. S., Li, G., 2011. A hybrid RANS and kinematic simulation of wind load effects on full-scale tall buildings. Journal of Wind Engineering and Industrial Aerodynamics 99 (11), 1126-1138.

Jones, W. P., Launder, B. E., 1972. The prediction of laminarization with a two-equation model of turbulence. International Journal of Heat and Mass Transfer 15 (2), 301-314.

Lateb, M., Masson, C., Stathopoulos, T., Bédard, C., 2010a. Numerical simulation of pollutant dispersion around a building complex. Building and Environment 45 (8), 1788-1798.

Lateb, M., Masson, C., Stathopoulos, T., Bédard, C., 2010b. Influence of turbulence models on pollutant dispersion studies around a building complex. In: The Fifth International Symposium on Computational Wind Engineering (CWE2010), Chapel Hill, NC, USA, 1-8.

Lateb, M., Masson, C., Stathopoulos, T., Bédard, C., 2011. Effect of stack height and exhaust velocity on pollutant dispersion in the wake of a building. Atmospheric Environment 45 (29), 5150-5163.

Li, W. W., Meroney, R. N., 1983a. Gas dispersion near a cubical model building: Part I. Mean concentration measurements. Journal of Wind Engineering and Industrial Aerodynamics 12 (1), $15-33$.

Li, W. W., Meroney, R. N., 1983b. Gas dispersion near a cubical model building: Part II. Concentration fluctuation measurements. Journal of Wind Engineering and Industrial Aerodynamics 12 (1), 35-47.

Li, Y., Stathopoulos, T., 1997. Numerical evaluation of wind-induced dispersion of pollutants around building. Journal of Wind Engineering and Industrial Aerodynamics 67-68, 757-766.

Lien, F. S., Yee, E., Cheng, Y., 2004. Simulation of mean flow and turbulence over a 2D building array using high-resolution CFD and a distributed drag force approach. Journal of Wind Engineering and Industrial Aerodynamics 92 (2), 117-158.

Lien, F. S., Yee, E., Ji, H., Keats, A., Hsieh, K. J., 2006. Progress and challenges in the development of physically-based numerical models for prediction of flow and contaminant dispersion in the urban environment. International Journal of Computational Fluid Dynamics 20 (5), 323-337.

Mavroidis, I., Griffiths, R. F., Hall, D. J., 2003. Field and wind tunnel investigations of plume dispersion around single surface obstacles. Energy and Buildings 37 (21), 2903-2918.

Meroney, R. N., Leitl, B. M., Rafailidis, S., Schatzmann, M., 1999. Wind-tunnel and numerical modeling of flow and dispersion about several building shapes. Journal of Wind Engineering and Industrial Aerodynamics 81 (1-3), 333-345.

Murakami, S., 1993. Comparison of various turbulence models applied to a bluff body. Journal of Wind Engineering and Industrial Aerodynamics 46 (47), 21-36. 
Murakami, S., 1998. Overview of turbulence models applied in CWE-1997. Journal of Wind Engineering and Industrial Aerodynamics 74-76, 1-24.

Murakami, S., Mochida, A., Hayashi, Y., Hibi, K., 1991. Numerical simulation of velocity field and diffusion field in an urban area. Energy and Buildings 15 (3-4), 345-356.

Nakiboglu, G., Gorlé, C., Horváth, I., Beeck, J. V., Blocken, B., 2009. Stack gas dispersion measurements with Large Scale-PIV, Aspiration Probes and Light Scattering Techniques and comparison with CFD. Atmospheric Environment 43 (21), 3396-3406.

Nallasamy, M., 1987. Turbulence models and their applications to the prediction of internal flows: A review. Computers \& Fluids 15 (2), 151-194.

Patankar, S. V., Spalding, D. B., 1972. A calculation procedure for heat, mass and momentum transfer in three-dimensional parabolic flows. International Journal of Heat and Mass Transfer 15 (10), 17871806.

Pope, S. B., 2000. Turbulent flows. Combridge University Press.

Rodi, W., 1997. Comparison of LES and RANS calculations of the flow around bluff bodies. Journal of Wind Engineering and Industrial Aerodynamics 69-71, 55-75.

Saathoff, P. J., Stathopoulos, T., Dobrescu, M., 1995. Effects of model scale in estimating pollutant dispersion near buildings. Journal of Wind Engineering and Industrial Aerodynamics 54-55, 549559 .

Sada, K., Sato, A., 2002. Numerical calculation of flow and stack-gas concentration fluctuation around a cubical building. Atmospheric Environment 36 (35), 5527-5534.

Salim, S. M., Buccolieri, R., Chan, A., Di-Sabatino, S., 2011. Numerical simulation of atmospheric pollutant dispersion in an urban street canyon: Comparison between RANS and LES. Journal of Wind Engineering and Industrial Aerodynamics 99 (2-3), 103-113.

Shih, T. H., Liou, W. W., Shabbir, A., Yang, Z., Zhu, J., 1995a. A new $k-\epsilon$ eddy viscosity model for high Reynolds number turbulent flows. Computers \& Fluids 24 (3), 227-238.

Shih, T. H., Zhu, J., Lumley, J. L., 1995b. A new Reynolds stress algebraic equation model. Computers Methods in Applied Mechanics and Engineering 125 (1-4), 287-302.

Shirasawa, T., Yoshie, R., Takana, H., Kobayashi, T., Mochida, A., Endo, Y., 2008. Cross comparison of CFD results of gas diffusion in weak wind region behind a high-rise building. In: The 4th International Conference on Advances in Wind and Structures (AWAS'08), Jeju, Korea, 1038-1050.

Stathopoulos, T., Hajra, B., Bahloul, A., 2008. Analytical evaluation of dispersion of exhaust from rooftop stacks on buildings. In: Report R-576. Institut de recherche Robert-Sauvé en santé et en sécurité du travail (IRSST), Montreal, Canada, IRSST/Report-576.

Stathopoulos, T., Lazure, L., Saathoff, P., Gupta, A., 2004. The effect of stack height, stack location and rooftop structures on air intake contamination: A laboratory and full-scale study. In: Report R-392. Institut de recherche Robert-Sauvé en santé et en sécurité du travail (IRSST), Montreal, Canada, IRSST/Report-392.

Tominaga, Y., Mochida, A., Yoshie, R., Kataoka, H., Nozu, T., Yoshikawa, M., Sharasawa, T., 2008. AIJ guidelines for practical applications of CFD to pedestrian wind environment around buildings. Journal of Wind Engineering and Industrial Aerodynamics 96 (10-11), 1749-1761.

Tominaga, Y., Stathopoulos, T., 2007. Turbulent Schmidt numbers for CFD analysis with various types of flowfield. Atmospheric Environment 41 (3), 8091-8099. 
Tominaga, Y., Stathopoulos, T., 2009. Numerical simulation of dispersion around an isolated cubic building: Comparison of various types of $k-\epsilon$ models. Atmospheric Environment 43 (20), 3200-3210.

Tominaga, Y., Stathopoulos, T., 2010. Numerical simulation of dispersion around an isolated cubic building: Model evaluation of RANS and LES. Building and Environment 45 (10), 2231-2239.

Wang, X., 2006. Numerical simulation of wind-induced dispersion of emissions from rooftop stacks. M.A.Sc Thesis, Department of Building, Civil and Environmental Engineering, Concordia University, Montreal, Canada, 1-150.

Wright, N. G., Easom, G. J., 2003. Non-linear $k-\epsilon$ turbulence model results for flow over a building at full-scale. Applied Mathematical Modelling 27 (12), 1013-1033.

Xie, X., Huang, Z., Wang, J. S., 2005. Impact of building configuration on air quality in street canyon. Atmospheric Environment 39 (25), 4519-4530.

Xie, X., Liu, C. H., Leung, D. Y. C., Leung, M. K. H., 2006. Characteristics of air exchange in a street canyon with ground heating. Atmospheric Environment 40 (33), 6396-6409.

Yakhot, V., Orszag, S. A., Thangam, S., Gatski, T. B., Speziale, C. G., 1992. Development of turbulence models for shear flows by a double expansion technique. Physics of Fluids A4, 1510-1520.

Yang, Y., Shao, Y., 2008. Numerical simulations of flow and pollution dispersion in urban atmospheric boundary layers. Environmental Modelling \& Software 23 (7), 906-921.

Yassin, M. F., Kellnerova, R., Janour, Z., 2008. Impact of street intersections on air quality in an urban environment. Atmospheric Environment 42 (20), 4948-4963.

Zhai, Z. J., Zhang, Z., Zhang, W., Chen, Q. Y., 2007. Evaluation of various turbulence models in predicting airflow and turbulence in enclosed environments by CFD: Part 1-Summary of prevalent turbulence models. HVAC\&R Research 13 (6), 853-870.

Zhou, J., Kim, C. N., 2010. Numerical investigation of indoor $\mathrm{CO}_{2}$ concentration distribution in an apartment. In: 3rd International Symposium on Sustainable Healthy Buildings (SHB2010), Seoul, Korea, 325-337. 